far to the sou'h as the Pyrences in the palocolithic age, an: 1 that the Basque or Iberic population ranged as far north as the British Isles.

THE "Astronomical Observations taken during the years IS7O-72, at the private observatory of Mr. Joseph Gurney Burclay, Leyton, Essex," by Mr. C. C. Talmage, contains well-arranged tables of double star observations, followed by copious notes on the observations, and occultations, and phenomens of Jupiter's satellites. Mr. Barclay thinks it so advisable to reduce and print observations at short intervals, that he has determined, wisely we think, to adept the plan without waiting for a number to furm a large volume.

Axovg Messrs. Smith, Eller and Co.'s announcements of forthcoming werks, we observe the following : $-A$ translation of Prof. "Heririann's Elements of Physiology," by Dr. Arthur Gamgee; and "A Text Book of Parhologrical Anatomy," by John Wyilie,' M.D., Lecturer on Cieneral Pathology at the School of Medicine, Surgeons' Hall, Eilinburgh.

A.MoNG Mr. Robert IIardwicke's autumn announcements we notice the following scientific buoks-"NIan and Apes:" an Exposition of Structural Rejemblances and Differences bearing upon questions of affinity and oriria, by St. Geo ge Mlivart, F.R.S. This work will be published simultaneously in $A$ !nerica and Encland. "Waste Products and Undeveloped Substances :" a synopsis of prigress during the last quarter of a century at home and abroad, by P. L. Sinmonds, the editor of the "Jourmal of Applied Science." "Where there's a Will there's a Way; or, Science in the Cottage," by James Cash ; beins an account of the labours and lives of sone north-country botanists in humble life. "The British IIepr'ica," with descriptions by Dr. Carrington, and drawings by J. E. Sowerby. This will he issued in twelve monthly parts. "Ifonker's Synopsis Filicun," a new edition brought up to the present time by J. G. Bsker, Royal Herbarium, Kew. " On Mounting Microscopic Objects," by Thomas Davies. A new edition, much enlarged, by John Matthews, MI.D., F.R.M.S. Tiis last-named work is neatly ready for publication.

The library of the Manchester Athencum was destroyel by fire on Sept. 24. The damage, estimated at $10,000 \%$, is said to be wholly covered by insurance.

WE have received the programme of the Edinburgh Vete. rinary College. We hope that, under the superintendence of the new Principal, Prof. Fearnley, this imporiant institution will become more prosperous than it has ever been, and that the principles of the veterinary ast will be taught in a thoroughly scientific way. That this is likely to be the case may be seen from the following list of professors :-Dr. Balfour, F.R.S., Dr. Muric, Mr. Dewar, F.R.S.E., Dr. Young, and Mr. Wally.

THe following are some of the most important recent additions to the Brighton Aquarium :-2 Octopus (O. izulgurls); I Group of Barnacles (Lepas Hillui) ; 30 Sea-horses (Hippocampus ramulosu(s) ; 5 African Crocodiles; 2 Alligator Terrapus (Chil)ara serpenttna); I Edible Turtle (Chclonia midas); I Sturgeon (Acipenser sturio).

THE additions to the Zoological Society's Gardens during the past week include a Brown Capuchin (Ccbus fatuellus) from Guiana, and two Bomnet Monkeys (Mracacus ratiatus) from Inlia, presented by Lord Louth; two Crested Ground Para. keets ( Calopsitta novichollandic) from Australia, presented by Miss L. E. Lyon, and two hatched; four Alpacas (Lama pacos), two Llamas (Lama fertana) from Peru, a Vicuna (Lama zicusna) from South America; a Cuvier's Gazelle (Gotslla cuitieri) from Muscat; a Sultry Hermipode (Ortyxelos meiffeni) from Vest Africa; a Southern Mynah (Acridotheres mahrat. tensis) from S. India, deposited; a Philantomba Antelope Cephalophus. $\pi$ b.xivilli) from Sierra Leone, received in exchange.

\section{MOLECULAR EVOLUTION}

Ar quite uncertain times and places The atoms left their heavenly path,

And by fortuitous embraces

Engendered all that being hath.

And though they seem to cling together And form "associations" here,

Yet, late or soon, they burst their tether, And through the depths of space career.

So we, who sat, oppressed with Science, As British $A$ sses, wive and grave,

Are now transformed to fierce Red Lions, As round our prey we ramp and rave.

Thus by a swift metamorphōiis, Wistom turns wit, and Science jrike ; Nonsense is inceuse to our noses,

For when Red Liuns speak they smoke.

IIail, Nonsense ! dry nurse of Rell Lions, * From thee the wise their wisclom learn,

From thee they cull thos truths of science Which into thee sigain they turn.

What combinations of iteas Nonsense alone can wisely form,

What sage has half the power that she has To take the towers of Truth by storm?

Yield, then, ye rule; of rigid rexson! Dissolve, thuu too, too solid srnse !

Melt into nonsense for a season, Then in some higner furin cundense.

Soon, ah! ton soon, the chiliy morian Tris flow of soul will crystallise,

And those who no: sense now are sc.rning May learn too late where wisdjon lies.

\section{THE BRITISH ASDOCIATION}

$\mathrm{W} W \mathrm{E}$ are glad to say that the attendance at the Brad. furd Meeting was considerably larger than was at first stated. The tutal number of persons who attende ! the meeting is 1,983 , and the total amount received, $2,102 l$.

The following is a list of the grants of money appropriated to scientific purposes by the Genera! Committee :-

\section{Mathematics and Physics}

\& s. $d$

Cayley, Pros.-Mathematical Talles

$100 \quad 0 \quad 0$

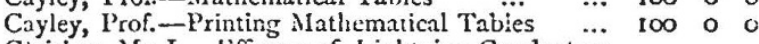
Glaisher, Mr. J.-Efficacy of Lightning Conductors

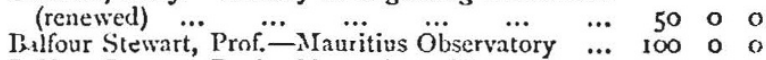
$\begin{array}{llrrr}\text { Balfour Stewart, Prof.-Magne ism of Iron } & \ldots & 20 & 0 & 0\end{array}$

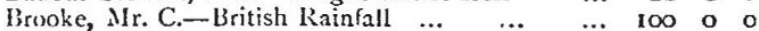

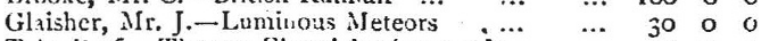

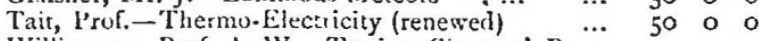
Williamson, Prof. A. W.-Testing Sienens' Pyro$\begin{array}{lllllllll}\text { meter (renewed) } & \ldots & \ldots & \ldots & \ldots & \ldots & 30 & 0 & 0\end{array}$

\section{Chemistry}

Brown, Prof. Crum.- High temperature of Bodies (partly renewed).$\dddot{W}$. $\ldots$ kecords of the Progress $\begin{array}{lllllllll}\text { of Chemistry } & \ldots & \ldots & \ldots & \ldots & \ldots\end{array}$ Gladstone, Dr.-Chemical Constitution and ${ }_{0}$. $\ldots$ tical Properties of Eisential Oils $\quad \ldots \quad \ldots \ldots$... Armitrong, Dr.-Isonaric Cresols and their De:i$\begin{array}{lllllllllll}\text { vatives } & \ldots & \ldots & \ldots & \ldots & \ldots & \ldots & 20 & 0 & 0\end{array}$ Canied forward $\chi_{7}$ So o 6 " "Leonxm arida nutrix."

\section{7o 0}

10000

100

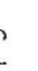




\section{$\begin{array}{lllllllll}\text { Brought forward } & \ldots & \ldots & \ldots & \ldots & \ldots & \ldots 7 \text { So } & \circ & \circ\end{array}$ \\ Herschel, Prof.-Thermal Conducting Power of}

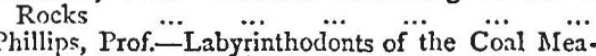
sures
Bryce, Dr. Collection of $\dddot{\text { Fossils }} \cdots$
in the North. Viest of Scotland ...

IViltshire, Rev. T. - Investigation of Fossil Corals villett, Mr. H. - The Sub-Wealden Exploration... Lyell, Sir C. - Kent's Cavern Exploration

Harkness, Prof.-Mapping Positions of Erratic Rocks and Boulders

Wondward, Mr. H.-Record of G̈eological and

Palxontological li terature ...
Lubbock, Sir J. - Exploration of Victoria Cave Biology

Lane-Fox, Col. A.-Forms of Instruction for $\mathrm{c}$ Travellers (25l. renewed)

Stainton, Mr. - Record of the Progress of Zoology Jeffreys Mr. Gwyn.-Dredging off the Ccasts of Yorkshire

Mckendrick, $\dddot{D} r$. - Physiological $\dddot{A}$ ction of Light Brunton, Dr.-The Nature of Intestinal Secretion Foster, Dr. M. - Mrethods of Breeding the Embryos of Delicate Marine Organisations
Statistics and Economic Science

Statistics and Economic Science
Houghton, Lord.--Economic Effects of Trades Unions

$$
\text { Mechanics }
$$

Froude, Mr. W.-Instruments for Measuring the Speed of Ships and Currents (renewed)

Io 00

ro 00

10 00

2500

2500

15000

I0 0 o

$100 \quad 0$

5000 10000

3000 20 o 0 2000 3000 2500 $50 \quad 00$

Widow of the late Mr. Askham (Clerk to the Association)

\section{SECTIONAL PROCEEDINGS \\ SECTION A.-MATHIMATICS}

Refort of the Luminous Meteor Committe of the British Asso. ciation on Observations of Shooting.stars in $1872-73$.

Shooting-stars and large fireballs have appeared during the past year in more than usual varieties. Iarge metcors have pre. sented themselves in considerable numbers, and ordinary shooting-stars in a more striking manner as regards the explanation of their origin than bas often been the case in former years. Of all these kinds of shonting-stars, both large meteors and meteoric showers, much accurate information has reached the committee; but the extent of the knowledge acquired on all hands, has at the same time advanced so rapidly, that a smaller amount of attention has this year becn directed towards the discussicn of the individual descriptions, than the committee have hitherto bestowed upon them, and a more complete reduction of the separate observations will accordingly be attempted when the opportunities of the com mittee allow of their closer examination.

Those meteors, however, which have been observed simultaneously at moe than one observing station have been selected from the collection for transcription in suitable columns in this report, and a list of large metenrs is added, among which some have occurred that have without doubt been noticed, and may have attracted attention in other directions, than has hitherto come to the knowledge of the committee. Two of the largest fire-halls scen in Great Britain were aërolitic, or burst with the sound of a violent explcision on November 3 and February 3 last. The first passed over the cen ral part of Scotland, and the econd burst over Manchester and its neighbourhocd at half-past five, and at 10 o'clock respectively on the evenings of those days. Aërolitic meteors and aëroli es have also been noticed in the scientific journals of other countries, which have given rise to experinients on the composition of aërolitic substances, both chemical and microscopical, the corclusions of which continue to extend the range of our speculations regarding the origin of these bodies. Thus the existence of carbon and hydrogen in the atmosphere from which the largest iron meteorite yet $f($ und (a few years since upon the shores of Greenland) was expelled, confirms the discoveries of Grahame and Professor Mallet, in America, of the existence of the same gases in other meteoric irons. Dr, Wöhler has thus detected the oxides of carbon as gases in the vast meteoric iron of Ovifak found in Greenland, and brought to Stockholm during the last few years by Prof. Nordenskiö!d, and the same gas was found by Prof. Laurence Smith in the siderite which fell recently in the United States. $\Lambda$ connection between comets and meteorites appears to be indicated by these discoveries, in the spectra of some of which gases containing carbon appear to have been certainly recognised by Dr. Huggins.

The past year was distinguished by the occurrence of a most remarkable star shower on the night of November 27 last, to the expected appearance of which astronomers were looking forward with especial attention from the unexplained absence of the double comet of Biela (to which it belongs) from its accustomed returns in the last three of its periodical revolutions. The probability of the comet's path being marked by a meteoric stream into which the earth might plunge on or about Nov. 27 every year was already become a certainty, by the observation of such a meteoric stream on Nov. 30,1867 . On that night M. Zezioli of Bergamo, observed a distinct star-shower, according to Schiaparelli, no doubt of whose belonging to the missing comet could be entertained. Although the exact date of the shower could not be accurately foretold with certainty from the want of recent observations of the comet, yet every probability of its being seen was favourable to its reappearance last year, and those who awaited it, as well as many unexpected watchers of meteor-showers, were surprised by the brilliant spectacle which it suddenly presented. At the first approach of darkness on the evening of Wednesday the 27th of November last, the cloudy state of the sky unfortunately deprived observers in the south of England from witnessing the sight, but in Scotland, and north of the Midland Counties of England many uninterrupted views of it were obtained. On the European continent and in the United States of America, as well as in the East Indies, at the Mauritius and in Brazil observers were equally fortunate in recording its ap. pearance, and few great star-showers have hitherto been more satisfactorily observed, or indeed more abundantly described. In an astronomical point of view the agreement of the time and other circumstances of its appearance with the supposed path of the lost comet is so exact as to prove that the calculations made by astronomers of that comet's orbit cannot be affected by any errors of a large sensible amount, and a proof almost certain is thus obtained that the disappearance of the comet is owing to no un explained disturbances of its path; but that like some former comets of variable brightness, it has not improbably faded for a time out of view, and that at a future time a reasonable expecta. tion may be entertained of re-discovering it pursuing its original path in repeated visits to the earth's neighbourhood, and to the field of telescopic observation.

Only partial views of the ordinary periodical meteor showers of December, January, and April last were obtained, of which some descriptions are contained in the Report.

Reductions of the scattered meteor-observations on ordinary nights of the year are an important subject of the Committec's inquiries, which have been kept in view in their operations of the past year. Captain Tupman having obligingly placed a list of nearly $6, \infty$ such observations (made by himself) at their disposal, the greater part of which he has reduced to their most conspicuous radiant points, the present purpose of the Committee is most effectually obtained by the publication of the valuable meteor list which has thus unexpectedly come into their posses. sion; and a graphic projection of the radiant points has been prepared, which will be printed as an illustration of the copious information that will be gathered by observers from the contents of Captain Tupman's list. The catalogue $w$ ill be distributed this year to observers interested in the research; and to enable suitable lithographic charts to be added to it, it is hoped that the members of the British Association will assist the Committee with such liberal communications of their observations as they have hitherto abundantly supplied.

Note on a Natnral Limit to the Sharfness of the Stuctral Lives, by Lord Rayleigh, F.R.S.

In the explanation ustally given of the broadening of the fixed lines with increased pressure, it appears to be assumed that their finite width depends on the disturbance produced by the mutual influence of the colliding moleculos. I desire to point out that even if each individual molecule were allowed to execute its vibrations with perfect regularity, the resulting spectral line 
would still have a finite width, in consequence of the motion of the molecules in the line of sight. If there is any truth at all in the kinetic theory of gases, the molecules of sodium, or whatever the substance may be, are moving in all directions indifferently, and with velocities whose nragnitudes cluster about a certain mean. The law of distribution of velocities is probably the same as that with which we are familiar in the theory of errors, according to which the number of molecules affected with a given velocity increases, the nearer that velocity is to the mean.

By the principles of this theory of gases the mean square of the velocity of the molecules can be deduced from the known pressure and mass. If $v$ denote the velocity whose square is cqual to the mean, it is found that for air at the freezing-point, $v={ }_{4} S_{5}$ metres per second.

At the temperature of flame, the velocity may be about three times greater. For the purposes of a rough estimate it will be accurate enough to take the mean velocity of the molecules at I,500 metres per second, and that of light at 300,000,000 metres per second. The wave-lensth of the light emitted by a molecule moving with the mean velocity from the eyc will therefore be greater by about five millionths than if the molecule were at rest. The double of this will be a moderate estimate of the width of the spectral line, as determined by the cause under consideration. We may conclude that however rare the gas, and however perfect our instrument may be, a fixed line cannot be reduced to within narrower limits than about a hundredth part of the interval between the sodium lines. I must leave it to spectroscopists more practised and skilful than myself to say whether this result is in agreement with the appearance of the spectrum.

\section{SECTION B.-CHEMISTRY}

The report of the Committee appointed to examine the Methods of making Gold Assay's and stating the Results thircof, was read by MIr. WV. C. Roberts.

The report stated that although the amount of alloy. in gold could be ascertained to within a maximum error of $0^{\circ}$ or per cent., or one ten-thousandth part, yet there was an amount of difference between the results obtained by different assayers which required an explanation. The committee considered that the difference between different assayers was too great to be accounted for by the ordinary causes of error in analysis, and they had therefore come to the conclusion that the nominally assayed gold must have contained some impurity which had escaped the assaying process. The committee had precipitated eiglity ounces of gold from no less than a hundred gallons of chloride of gold, and they suggested that the gold this ohtained might be used as a standard with which the gold assayed by different assayers might be compared.

MIr. A. Vernon İarcourt, I.R.S., and MIr. F. Wr. Fison, F.C.S., explained a Conlinuous Process for Furifyingr Coal Gas and obtaining Sulplutr and Ammonium Sulphate.

Mr. Vernon Ifarcourt said that the usual method of freeing coal gas from sulphuretted hydrogen was by passing it through lime. But oxide of iron was also employed in place of the lime, the advantage possessed by the oxide being that whilst the lime, after it had served its purpose, was useless and difficult to get rid of, the oxide of iron could be used repeatedly for the same purpose. The chemical changes involvcd were, that when the gas had passed through the oxide the latter was changed into sulphide of iron; when the sulphide was exposed to the air, the sulphur separated and the oxide was re-formed, thus enabling the oxide to be again used. This was called a continuots process, because the oxide could be continuously used. Iut the process was not quite continuous, for after the oxide had been used some thirty times, it became so clogged with sulphur as to be useless. The advantage of the process he was about to describe was that the oxide couid be used over and over ad infinitum; and, besides, the ammonia was secured in a marketable form. The present method of freeing gas from ammonia by "scrubbing," or passing it through a large receiver containing a small quantity of water spread oser a large surface, had one or two defects. It did not secure the ammonia in a good form, and it probably diminished the illuminating power of the gas, for olefiant gas was soluble in water. The new process was applicable wherever oxide of iron could be used in the purifying process. The difference from the oid process was that the oxide during revivification was moistened with a solution of ferric sulphate (per sulphate of iron), and a portion of the oxide was removed from time to time, and treated as follows :- It was first extracted with water by the use of a well-known arrangement. The soluble salts were sulpliate of ammonia-formed in the purification by the reaction of ammonia upon ferric sulphate-and, in smaller quantities, sulphocyanide, hypo-sulphite, and probably sulphate of ammonia. This extract was mixed with a small excess of sulphuric acid; and yielded when concentrated by evaporation, crystals of anmonium sulphate. The remainder of the substance was then boiled with dilute sulphuric acid, which dissolved the oxide and left a residue of sulphur. The actual process of extraction by acid consistcd in treating the substance successively with (I) a solution of ferric sulphate containing some free sulphuric acid; (2) with a more dilute solution of ferric sulphate to which sulphuric acid had been added; $(3$ and 4 ) with more dilute solutions of ferric sulphate - all these liquids being the product of a former extraction - and (5) with water. The liquid resulting from the first of the treatments enumerated above was a strong solution of ferric sulphate, which was used as already mentioned, by being mixed with the charge of oxide before it was replaced in the purifier. The residue of the final washing consisted almost entirely of sulphur, and required only to be dried. It would be evident that all the oxide which had been freed from sulphate of ammonia and sulphur by this treatment passed into the condition of ferric sulphate, and in this condition it was replaced in the purifier. There it again became oxide by the action upon it of the ammonia in the gas, which it completely removed, fixing it as sulphate. This system had been brought into use as a manufacturing process, and had been found to be, as far as could be judged, a complete success.

Mr. Fison explained at length the apparatus by which the pro. cess was carried into effect.

Mr. J. Spiller, F.C.S., gave a short communication on Artificial NYagnctile, the object of which was, first, to point out an error in the statement of a chemical reaction occurring in several standard works of reference; and, in the second place, to indi. cate the formation of crystallised magnetic oxide of iron (mag. netite) in the ordinary process of manufacturing aniline from nitro-benzol by the reducing action of metallic iron. Reference was made to "Reimann's Aniline and its Derivatives," and to Vagner's "Chemical Technology," where the action of iron upon nitrobenzol in the presence of acid (Béchamp's process) is stated to give ferric oxide, or a "hydrated oxide of iron." The author pointed to the fact that the ordinary residual product in this operation was black, and could be so far purified by washing and elutriation from the cxcess of iron, usually remaining in ad. mixture, as to give a fine black pigment, which appeared under the microscope as minute octohedra, and was strongly magnetic. Chemical analysis showed this to consist almost entirely of mag. netic oxide of iron, with such impuritics as were inherent to the process, or previously existed in the cast iron. The physical properties of this form of oxide were further described, and its analogy to the native varieties of magnetic ore (Comish and Dannemora) shown.

MIr. W. C. Roberts exbibited some specimens of artificial horn silver which he had formed by mixing strong solutions of silver nitrate and common salt.

Prof. Schafarick, of Prague, read a paper On the Constitution of Silicates, in which he developed his views as to the manner in which certain members of this class of bodies might be graphically represented.-Prof. Crum Brown, whilst complimenting the author on the importance of the step taken, pointed out that we should guard against confusing graphic' formulx, as applied to minerals, with those applied to organic substances, because they do not represent the same kind of knowledge. Structural formula in organic substances represented reactions, and not merely composition; in the case of minerals we had as yet no method of following their reactions.

Prof. Crum Brown then read a paper On the Action of Sulphide of Mrthyl c1 Bromacetic Acid. He said bromacetic acid dissolved readily in sulphide of methyl. The solution soon be. came warm and separated into two layers, the lower of which solidified into a white crystalline mass. The crystals were easily purified by washing with absolute alcohol, in which they were very sparingly soluble. Analysis had given a result for this compound which showed it to be a compound of one molecule of bromacetic acid, and one of sulphide of methyl. The compound was obviously analogous to hydrobromate of betain.

Ir. Jesse Lovett described an improved gas-burner, 
simply a modification of Wallace's yas-burner. The improvement consisted in a simple mechanism whereby the air and gas could be shut off by one movement.

\section{SECTION C.-GEOLOGY}

Second Rifort on the Discoucry of Fossils in certain remote farts of the N'orth-itestern Highlands, by W. Jolly.

During the past year search las been made at various points along the great limestone strike of the North-western Highlands, but, with the exception of the Durness basin, from which the fossils already collected have been alone obtained, none have been found at any new locality. It is most desirable that continued search should be made for fossils, and to determine if the fossiliferous Durners limestone be the same as that in the line of strike from Eribol to Skye.

Rieport on Earthquakes in Scotland, by Dr. J. Bryce, F.G.S. Last. year a report on this subject was read at Brighton, stating that there had been but little to record during the year then reportcd on ; but whilst the Association was sitting a shock occurred in the Comrie district, an account of which is given in the report now presented. The earthquake occurred on $A$ ug. $S$. IS72, at from Sm. to 10m. past 40 'clock in the afternoon. The successive phases, according to almost all the observers, were :a noise or sound, loud, heavy, and rumbling; a shock with a shaking and rattling of objects; and a wave-like motion of the grourd. The undulations appear to have come from the WV. or N.W.; according to some observers, from the opposite direction; but these probally did not distinguish between the first impulse and the recoil.

The extent of country through which the shock was felt is greater than that of any which has occurred since this in quiry was undertaken. The limits are marked by Stirling and Blair Logie on the S.E., and by St. Fillans on Loch Earn, and GIen Lednock on the N. IV. The shock was feebler at their limits than in the country between, as about the bridge of Allan, Dunblane, \&.c. The breadth of the disturbed area does not appear to have extended more than two or three miles from the Allan VYater; the shock seems to have emanated near Comric. The geological formations of the district are very various in character, and it does not appear that any connection can be traced between the natture of the rock forming the surface and the severity of the shock.

Another shock, which occurred at 9.55 P.M. on April 16 1873 , is briefly described. This was in the South of Scotland, in the parishes of Tyrone, Glencairn, and others adjacent. $\Lambda \mathrm{c}$ cording to one observer, there was another shock in this district at $2.46 \mathrm{A.1s}$. on the following morning.

Report of the Commilte for Explorings the Sette Cazt, by W. Isoyd Dawkins, F.R.S.

This care is of great interest, and is being explored by a local committee, aided by a grant from the British Association. In the newest layers there is evidence of hunian occupation during the historic period; but in the older cave earth, which contains the remains of extinct mammalia, no trace of man has yet been discovered. The exact age of the cave earth is a matter of dispute. Mr. Tiddeman, from the physical evidence alone, regards it as pre-glacial, or rather as older than the great icesheet of that district. Mr. Dawkins, whilst doubting the physical evidence afforded by the cave alone, is inclined to regard the fauna as pre-glacial, and he remarks:- "It is obvious that the hycenas, bears, mammoths, and other creatures found in the pleistocene stratum could not have occupicd the district when it was covcred by ice; and had they lived soon after the retreat of the ice-sheet, their remains would occur in the river-gravels, from which they are absent throughout a large area to the north of a line drawn between Chester and York, whilst they occur abundantly in the first glacial river deposits south of that line. On the other land, they belong to a fauna, that overran Europe, and must have occupied this very region, before the glacial period. It may, therefore; reasonably be concluded that they occupied the cave in pre-glacial times, and that the stratum in which their remains lie buried, was prctected from the grinding of the ice-sheet, which destroyed nearly all the surface accumulations in the river-valleys, by the walls and roof of rock, which_has since, to a great extent, weathered away."

Report of the Bowlder Conmittee, byjRev, H. W. Crosskey, F.G.S.
This committee was appointed at the Brighton meeting to collect and tabulate information upon the distribution of erratic blocks throughout England and Wales. Good work has already been done in Scotland by a committee formed for a similar purpose. It is evident that some steps should at once be taken to record the existence of remarkable blocks, and if possible to take some steps to ensure their preservation.

The report, which is necessarily chiefly preliminary, clescribes the distribution of boulders around Charnwood Forest, and refers to the existence of Charnwood Forest boulders in Shrop. shire. It also contains a notice, by Mr. Pengelly, of a large granite boulder below the raised beach in Barnstaple Bay. An account is given of the place adopted by the Geological Section of the Birmingham Natural Ifistory Society for mapping the boulders of their district, a plan so effective that we reproduce the paragraph referring to it in the hopes that other districts'may follow the good example here sct. "The Ordnance map of the neighbourhood of Jirmingham has, in the first place, been divided by rulcd lines with squares of one inch wide, each sqquare enclosing a representation of one square mile of country. Enlarged maps, on the scale of six inches to the mile, were prepared from this. On these enlarged maps the boulders are to be marked by circles, the number of concentric circles repre. senting the diameter of one boulder in feet. For collecting specimens of the rocks of which the boulders are composed, bags were made and numbered, corresponding to each square on the map. At the same time notes were to be made of any specimce that was of unusual interest. Finally it was proposed to repre. sent, on a duplicate map, the number of boulders and the character of the rocks by discs of colour, so that a graphic representation of the boulders as to position, numbers, and kind of rock, would be given, and the source of any class of boulders, 2.5 granite $e . s$. , could be readily traced. It was further proposed to make a rough relief map of the district, so as to judge in what way the configuration of the country had affected the distribution of the boulders.

On the Whin Sill of Northumberland, by IV. Topley, F.G.S., and G. A. Lebour, F.G.S.

This paper, the result of work by the authors during the pro. gress of the Geological Survey, was laid before the section by permission of the Director-General of the Survey.

The basaltic rocks of the North of England occur in two forms, either as dykes cutting vertically through the rocks, or as bids lying amongst them. The intrusive character of the dykes is undisputed, but there is much uncertainty prevailing as to the character of the beds of basalt. The authors endeavoured to show that it too is intrusive, and has been forced in a melted state through the rocks long after their deposition and partial consolidation.

The Whin Sill is best known in Teesdale and along the face of the great Pennine escarpment. This district was only briefly alluded to, partly because it has already been often described, especially by Professors Sedgwick and I'hillips, but also because the intrusive character of the rock is less evident there than in Northumberland.

An account of the literature of the subject was then given, and a MIS. section of the Northumberland coast, made in IS22, by Sir Walter C. Trevelyan, Bart., was exhibited. Although the Whin Sill of more southern districts had been mentioned by earlier writers, it was not till the publication of Sir Walter Trevelyan's papet in the Wernerian Transactions for $\mathrm{IS2}_{3}$, that attention was drawn to the intrusive character of the rock.

The Whin Sill is a true basalt, and does not differ in appearance or composition from the whin -dykes of the district. In Teesdale it is very uniform in its position amongst the sedimentary strata; for this reason, and because it generally alters but slightly, if at all, the rocks above, Prof. Phillips, and most geologists who have given most attention to the Teesdale district, believe the whin to be of the same date as the beds amongst which it lies.

The object of the paper was to show that through Northumberland the Whin Sill is not so constant in position, that it frequently very greatly alters the beds above it as well as those below, and that, in numerous instances, it can be shown to cut through the strata in a manner that would be impossible with a contemporaneous bed. It also varies in position to an extent of more than 1000 feet, and often comes up, not in true beds, but in bosses.

Nothing can be certainly known as to the age of this Whin Sill. That it is later than the beds with which it is associated is 
certain, but many consideraticns lead to the inference that it may not be later than the latter part of the carboniferous period.

\section{SECTION D.-BroLOGY.}

DERARTMENT OF ANATOMY AND FIYYSIOLOGY.

The Localisation of the Functions in the Brain, by Professor Ferrier.

All are agreed that it is with the brain that we feel, and think and will, but whether there are certain parts of the brain devoted to particular manifestations is a subject on which we have only imperfect speculations or data too insufficient for the form ation of a scientific opinion. The general view is that the brain as a whole subserves mental operations, and that there are no parts specially devoted to any particular functions. This has been recently expressed by so high an authority as Professor Séquard. The idea rests cliefly on the numerous facts of dis ease with which wc are acquainted. There are cases where extensive tracts of brain are destroyed by discasc, or removed after a fracture, apparently with no result as regards the mind of the individual. Along with these facts we liave others which are very curious, and which hardly seem to agree with this doctrine. One of these is that when a certain part of the brain is diseased, in Aphasia, the individual is unable to cxpress himself in words. Other curious phenomena have been well described by Dr. Hugblings Jackson, viz,, that certain tumours cr pathological lesions in particular parts of the brain give rise, by the irritation which they licep up, to cpileptiform convulsions of the whole of one side, or of the arm or leg or the muscles of the face; and from studying the way in which these convulsions show themselves he was able to localise very accurately the seat of the lesion.

The great difficulty in the study of the function of the brain has been in the want of a proper method. When we study the function of a nerve, we make our experiments in two ways. In the first place, we irritate the nerve by scratching or by electricity, or by chemical action, and cbserve the effect ; and in the second place, we cut the nerve, and observe what is lost. In regard to the brain and nervous system, the method has been almost entirely, until recently, the method of section. It has been stated by physiolcgists that it is impossible to excite the brain into action by any stimulus that may be applied to it, even that of an electric current; they have, therefore, adopted the method of destroying parts of the brain. This method is liable to many fallacies. The brain is such a complex organ that to destroy one part is necessarily to destroy many other parts, and the phenomena are so complex that one cannot attribute their loss to the failure only of the parts which the physiologists have attempted to destroy.

About three years ago, two German physiologists, Fritsch and Hitzig, by passing galvanic currents through parts of the brains of dogs, obtained various movements of the limbs, such as ad. duction, flexion, and extension. They thus discovered an important method of research, but they did not pursue their experiments to the extent that they might have done, and perhaps did not exactly appreciate the significance of the facts at which they had arrived.

I was led to the experiments which I shall have to explain by the effects of epilepsy and of chorea, which have been explained to depend upon irritation of parts of the brain. I endeavoured to imitate the effects of discase on the lower animals, and determined to adopt the plan of stimulating the parts of the brain by electricity, after the manner described by Fritsch and Hitzig.

I operated on nearly a hundred animals of all classes-fish, frogs, fowls, pigeons, rats, guinea pigs, rabbits, cats, dogs, jackalls, and monkeys. The plan was to remove the skull, and keep the animal in a state of ccmparative insensibility by chloroform. So little was the operation felt that I have known a monkey, with one side of the skull removed, awake out of the state induced by the chloroform, and proceed to catch fleas or eat bread ard butter. W'hen the animal was exhausted I some. times gave it a little refreshment, which it took in the midst of the experiments.

First, as to the experiments on cats, I found that on applying the electrcde to a portion of the superior external convolution the animal lifted its shoulder and paw (on the opposite side to that stimulated) as if about to walk forward; stimulating other parts of the same convolution, it brought the paw suddenly back, or put out its foot as if to grasp something, or brought forward its hind leg as if about to walk, or held back its head as if astonished; or turned it on one side as if locking at something, according to the particular part stimulated. The actions produced by stimulating the various parts of the middle external convolution were a drawing up of the side of the face, a backward movement of the whiskers, a turning of the head, and a contraction of the pupil respectively. A similar treatment of the lower extermal convolution produced certain movements of the angles of the mouth; the animal opened the mouth widely, moved its tongue, and uttcred loud cries, or mewed in a lively way, sometimes starting up and lashing its tail as if in a furious rage. The stimulation of one part of this convolution caused the animal to screw up its nostrils on the same side; and, curiously enough, it is that part which gives off a nerve to the nostril of the same side.

Results much of the same lcharacter were produced by the stimulation of the corresponding or homologous parts of the rat, the rabbit, and the monkey. Acting upon the anterior part of the ascending frontal convolution the monkey was made to put forward its hand as if about to grasp. Stimulation of other portions acted upon the biceps, and produced a flexing of the fore-arm, or upon the zygomatic muscles. The part that appeared to be connected with the opening fof the mouth and the movement of the tongue was homologous with the part affected in man in cases of aphasia. Stimulation of the middle temporo-sphenoidal convolution produced no results; but the lower temporo-sphenoidal, when acted upon, caused the monkey to shut its nostrils. No result was obtained in connection with the occipital lobes.

These experiments, have an important bearing upon the diag. nosis in certain kinds of cerebral disease, and the exact localisa. tion of the parts affected. I was able to produce epileptic convulsions of all kinds in the animals cxperimented upon, as well as phenomena resembling those of chorea or St. Vitus's dance. The experiments are also important anatomically, as in. dicating points of great significance in reference to the homology of the brain in lower animals and in man, and likewise served to explain some curious forms of expression common to man and the lower animals. The common tendency, when any strong exertion is made with the right hand, to retract the angle of the mouth and open the mouth on the same side, had been stated by Oken, in his Natur-geschichtc, to be due to the homology be: tween the upper limbs and the upper jaw; the true explanation being that the morements of the fist and of the mouth are in such close relation to each other that when one is imade to act powcrfully the impression diffuses itself to the neighbouring part of the brain and the two act together.

The experiments have likewise a physiological significance. There is reason to believe that when the different parts of the brain are stimulated, ideas are excited in the animals experimented upon, but it is difficult to say what the ideas are. There is, no doubt, a close relation between certain muscular movements and certain ideas which may prove capable of explanation. This is supported by the phencmena of epileptic insanity. The most imfortant guide on the psychological aspect of the qucstion is the discase known as $A$ phasia. The part of the brain which is the seat of the memory of words is that which governs the morements of the mouth and the tongue. In Aphasia the disease is generally on the left side of the brain, in the posterior part of the inferior frontal convolution, and it is generally associated with paralysis of the right hand, and the reason might be supposed to be that the part of the brain affected is nearly related to the part governing the movements of the right hand.

It is essential to remember that the movements of the mouth are governed bi-laterally from each hemisphere. The brain is symmetrical, and I hold it to be a mistake to suppose that the faculty of speech is localised on the left side of the brain. The reason why an individual loses his speech when the left side of the brain is diseased is simply this. Most persons are right. banded, and therefore left-brained, the left side of the brain governing the right side of the body. Men naturally seize a thing with the right hand, they naturally therefore use rather the left side of the brain than the right, and when there is disease, there the individual fecls like one who has suddenly lost the use of his right arm.

I may, finally, briefly allude to the results of stimulating the different.ganglia. Stimulation of the corpora striata causes the limbs to be flexed; the optic thalami produces no result: the corpora quadrigemina produce, when the anterior tubercles are acted upon, an intense dilatation of the fupil, and a tendency to draw pack the head and extend the limbs as in opisthotonos; 
while the stimulation of the posterior tubercles leads to the production of all kinds of noises. By stimulating the cerebellum various movements of the eyc-balls are produced.

In the discussion which ensued Dr. Geo. Harley alluded to the effect of mental emotion on the bodily functions, and the possibility of producing disease by simply acting on the nerrous system. Referring to phrcnology, he said it was one thing to localise function in the interior of the brain, and quite another to specify functions by manipulating the external cranium ; and he quoted a saying of Flourens with reference to phrenology : "Les hommes qui la pratiquent sont des charlatans, et les hommes qui la croient sont des imbeciles."

Dr. Carpenter remarked that the great work of the brain is done in the cortical substance, and in Dr. Ferrier's experiments the first effect of the stimulus is upon that particular substance, producing an intensification of the circulation througl it; being in that respect different from the ordinary stimulation of a nerve which acts upon the fibrous substance of the medullary matter of the brain. IIe had long since expressed lis disbclief in phrenology, which maintained that the animal functions were placed at the back of the head, and the intellectual at the front. Dr. Ferricr's experiments tended to show that the real seat of the intellectual functions was in the posterior part of the brain.

Dr. Brunton, however, alluded to the faculty of will and of gelf-restraint as distinguishing man from the lower animals, and said that this was probably situated in the anterior part of the brain. It was noticeable that criminals, who were deficient in that faculty, possessed only a small portion of brain in front of the head.

Prof. Burdon Sanderson said that the stimulus in Dr. Ferrier's experiments was, contrary to Dr. Carpenter's supposition, exactly like the ordinary excitation of a nerve, and that the effect was produced in an extremely short space of time.

Note on Hitizinga's Experiments on Abiogentesis, by Dr. BurdonSanderson.

Under the title of a "Contribution to the Question of Abiogenesis," Prof. Huizinga has very recently published (Pfiiger's Archiv, vol. vii. p. 549) a serics of experiments which descrve notice as constituting a new and carefully worked out attempt to support the doctrine of spontaneous generation.

Prof. Huizinga begins his paper with the words Alulta ronascentur qua jam cccidere, using them as an expression of the recurring nature of this question. He then proceeds to say that he was induced to undertake his inquiry by the publication of the well. known work of Dr. Bastian (whom he compliments as having awakened the exhausted interest of physiologists in the subject), his special object being to repent the much-discussed turnipcheese experiment.

Everyone knows what Dr. Bastian's observation is. It is simply this, viz. that if a glass flask is charged with a slightly alkaline infusion of turnip of sp. g. 1015, to which a trace of cheese has been added, and is then subjected to ebullition for ten minutes and closed hermetically while boiling, and finally kept at fermentation temperature, Bacteria develop in it in the course of a few days. This experiment has been repeated by Huizinga with great care, and the accuracy of Dr. Bastian's statement of fact confirmcd by him in every particular; yet notwithstanding this he thinks the evidence afforded by these results in support of the doctrine so inadequate, that he, desiring to find such cvidence, has thought it necessary to repeat the experiment under what he regards as conditions of greater exactitude.

Huizinga's objections to Bastian's experiment are two. First, that when a flask is boiled and closed hermetically in ebullition, its contents are almost entirely deprived of air, and (2) that cheese is a substance of mixed and uncertain composition. To obviate the first of these objections, he closes his flasks, after ten minutes boiling, not by hermetically sealing them, but by placing over the mouth of each, while in ebullition, a porous porcelain piate which has just been removed from the flame of a Bunsen's lamp. The hot porcelain plate is made to adhere to the edge or lip of the flask by a layer of asphalt with which the edge has been previously covered. The purpose of this arrangenent is to allow air to enter the flask, at the same time that all germinal matter is excluded. It is not nicessary to discuss whether this is so or not.

To obviate the sccord objection he alters the composition of the liquid used : he substitutes for checsc, peptons, and for turnip infusion, a solution containing in a litre of distillacl water :-

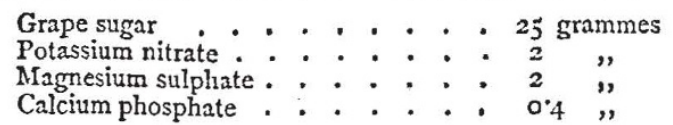

The phosphate is prepared by precipitating a solution of cal. cium chloride with ordinary sodium phosphate, taking care that the chloride is in excess. The precipitate of neutral phosphate so obtained is washed and then added to the saline solution in the proportion given. On boiling it is converted into soluble acid phosphate, and insoluble basic salt, of which the latter is removed by infiltration. Consequently the proportion of phos. phate in solution is less than that abore indicated.

To the filtrate, peptone is added in the proportion of $0.4 \mathrm{per}$ cent.

The peptone is obtained by digesting egg-albumen at the tem. perature of the body in artificial gastric juice made by adding the proper quantity of glycerin extract of pepsin to water acidulated with hydrochloric acid. The liquid so obtained is first rendered alkaline by the addition of liquor sodx, then slightly acidulated with acctic acid and boiled. The syntonin thus prccipitated is separated by infiltration from the clear jliquid, which is then evaporated to a syrup and poured in a thin stream into strong alcohol, with constant agitation. The precipitated peptone is separated after some hours and washed with alcohol, and redissolved in a small quantity of water. The solution is again precipitated by potiring it into alcohol in the same way as before, and the precipitate washed and dried.

Flasks having been half filled with the liquid thus prepared (in i, $, \infty, 2$ each of nitre ard Epsom salts, a trace of phosphate of lime, 25 parts of grape surar, and 4 parts of peptone), each is boiled for ten minutes, closed while boiling, with the earthenware plate as above described, and placed as soon as it is cool in the warm chamber at $30^{\circ} \mathrm{C}$. The experiment so made "gave, without any exception, a positive result in every case. After two or three day's the fluid was crowded with actively moving Bacterium termo."

The readers of NATURE are aware that in June last I published a repetition of Dr. Bastian's experiments with a variation not of the liquid but of the mode of heating (see NATURE, vol. viii., F. 141). Instexd of boiling the flasks for ten minutes jover the open flame and closing them in ebullition, I boiled them, closed them lermetically, and then placed them in a digester in which they wcre subjected to ebullition under a pressure of two inches or more of mercury. The result was negative. There was no development of Bacteria.

Since the publication of my experiments Huizinga's have appeared. If is result, regarded as a proof of spontaneous genera. tion is clcarly not superior to Hastian's. The substitution of a soluble immediate principle for an insoluble mixed product like cheese, and the use of a definite solution of sugar and salts are not material improvements. The question is not whether the germinal matter of Bacteria is present, but whether it is destroyed by the process of heating. Consequently what is necessary is not to alter the liquid but to make the conditions of the experiment as regards temperature as exact as possible. In this respect II uizinga's experiment is a confirmation of Bastian's and nothing more.

I have recently repeated it with the same modifications as regards temperature as those employed in my repetition of the turnip-cheese experinents. The result has been the same. In all other respects I have followed the method described by him in his paper.

I have prepared the solution of salts, grape sugar, and peptone in exact accordance with his directions. To obviate his objection as to the absence of air, I have introduced the liquid, not into flasks, but into strong glass tubes closed hermetically at each end and only half filled with liquid, the remzinder of the tube con. taining air at the ordinary tension. Each of these tubes, after having been subjected to the temperature of cbullition under two inches of mercury for half an hour, has been kept since September 10 at the temperature of fermentation $\left(32^{\circ} \mathrm{C}\right.$.). Up to the present time, no change whatever has taken place in the liquid.

As a control experiment I ppened one of the tubes immediately after boiling, and introduced a drup of distilled water. It became opalescent in twenty-four hours.

In conclusion let me olsserve that I still maintain my rezolution to take no side whatever in this controversy. I do not hold that spontancous generation is impossible. I do not regard heterogenists as scientific heretics. All I say is, that up to the 
present moment I am not aware of any proof that they are
right.

On the Electrical Phenomena which accompany the Contractions of the leaf of Dionaa muscipula, by Dr. BurdonSanderson.

It is well known that in those structures in the higher animals which are endowed with the property of contracting when stimulated-viz., nerve and muscle-this property is associated with the existence of voltaic currents which have definite directions in the tissue. These currents have been the subject of very careful observation by physiologists. They require delicate in. struments for their investigation, but the phenomena dependent on them admit of the application of the most exact measure. ments. The constant current which can be shown to exist in a muscle is called the normal current. The most important fact with reference to it is that it exists only so long as the muscle is alive, and that it ceases during the moment that the muscle is thrown into action. Other characteristics of the muscle currents rere referred to, which we have not space to mention.

In certain plants said to possess the property of irritability, contraction of certain organs on irritation occur which strikingly suggest a correspondence of function between them and the motor organs of animals. Among the most remarkable are those of Drosera and some other plants belonging to the same natural order, particularly the well-known Venus' Flytrap (Dionaa muscipula). The Sensitive Plant, the Common Monkey Flower, the Rock Cistus, aftord other examples.

Strange as it may scem the question whether these contractile movements are accompanied with the same electrical changes as those which occur in the contraction of muscle and in the functional excitation of nerve has never yct been investigated by vegetable physiologists. Mr. Darwin, who for many years has deroted much attention to the animal-like functions of Dionxa and Drosera, kindly furnished plants for the purpose of the necessary experiments, which have been made by Dr. Sanderson in the laboratory of University College, London. The result has been that the anticipations he had formed have been confirmed as to the existence of voltaic currents in these parts, and particularly in the leaf of Dionæa. By a most remarkable series of experiments (which will be published subsequently) made with the aid of Sir W. Thompson's maIranometer, he has shown that these currents are subject, in all respects in which they have been as yet investigated, to the same laws as those of muscle and nerve.

On Physiological Rescarches on the Nature of Cholera, by Dr. Brinton.

Without entering into the question of the nature of cholera poison, the writer regarded it as probable that its effects might be counteracted in the same way as those of other poisons-by appropriate antidotes. He supposed that if a poison could be found having a similar action to that of cholera, an antidote to the former might prove a remedy for the latter. The condition of cholera collapse has been attributed by Parkes and Johnson to contraction of the vessels in the lungs, and their theory is generally adopted. The writer fround that muscarin-an alkaloid denved from a specics of poisonous mushroom-caused contraction of the vessels of the lungs and some of the symptoms which are counteracted by atropia. It therefore seems probable that atropia might be useful in cholera, and in fact an American practitioner has recently employed large doses of it with success. The fact that nitrate of amyl, which also relaxes the pulmonary vessels, is useless as a remedy in cholera, as well as the absence of distension of the right side of the heart in cholera patients during life, shows that Parkes and Johnson's theory is imperfect, and that one of the most important conditions in cholera is active dilatation of the large veins in the interior of the body. The condition might be relieved by digitalis. The effect of this poison was at once observed in cholera. The rice water stools in cholera were stated to have exactly the same composition as the fluid secreted after the division of the intestinal nerves in Moreau's experiment, and the profuse secretion from the intestines in cholera was therefore attributed to paralysis of some of the intestinal nerves. Injection of Epsom salts into the intestines also product a profuse sccretion, though this might be due to irritation and not to paralysis of the nerves. This is not lessened in the least by atropia, and it seems therefore probable that atropia will not prove a perfect remedy for cholera. Dr. Brunton is still endeavouring to find a remedy which will arrest this secretion,
On the Moocments of the Glands of Droserd, by Alfred w. Bennett, F.L.S.

The peculiar movement of the glands which cover the margin and the upper side of the leaf of the Sundew has often attracted the attention of botanists. The observations were all made on the commonest species, Drosera rotundifolia.

It should be noted in the first place that the glands of Drosera are in no sense hairs, i.e. cellular expansions of the epidermis of the leaf. They have been shown by Groenland and Trécul to be an intcgral part of the leaf itsclf, penetrated by a fibro. vascular bundle with spiral threads (in other words by a vein or nerve of the leaf) from one end to the other, and even furnicherl with stomata on their surface. They terminate in a pellucirl knob within which is found their peculiar viscid secretion. Under a low magnifying power this secretion may be seen collected about the knobs, and stretching in thin glutinous strings from nne to another. The secretion has probably an attraction for flies and other small insects, as, if the plant is examined in its native bngs scarcely a leaf will be found in which an insect is not imprisoned, and one leaf will very often show as many as three or four. The experiment was made of placing a very small insect, a species of Thrips, on a leaf at that time quite unencumbered beneath a low power of the microscope. Immediately on coming into contact with the viscid secretion it made vigorous efforts to escape, hut these efforts only seemed to entangle it all the more deeply. The contact of the insect ap. peared to excite a stronger flow of the secretion, which soon enveloped the hidy of the animal in a dense almost transparent slime, firmly glueing down the wings, and rendering escape hopeless. It still, hnwcver, continued its struggles, a motion of the legs being still clearly perceptible after the lapse of three hours. During all this time the insect was sinking lower and lower down among the glands towards the surface of the leaf, hut only a slight change had taken nlace in the position of the glands themselves, which had slightly converged so as to imprison it more completely. But after the struggles of the prisoner had ceased, a remarkable change tonk place in the leaf. Almost the whnle of the glands on its surface and its margin, even those re. moved from the body of the insect by a distance of at least double its own length, began to bend over, and point the knobs at their extremities towards it, though it was not observed that this was accompanied by any increased flow of the secretion from them. The experiment was made in the erening; and by the next morning almost every gland of the leaf was pointing towards the nbject in the centre, forming a dense mass over it. The sides of the leaf had also slightly curved forwards so as to render the leaf itself more concave. The nearly allied Venus's Fly-trap, or Dionca muscifula of the United States, which im. prisons flies by a much more surden motion of the sides of the leaf, collapsing when irritated on the upper surface, is said to digest and absolutely consume the insects thus en. trapped. What becomes eventually of the nriconers of the sun. dew, my experiments have not been carried sufficiently far to ascer. tain. It will be seen that the most singular feature in the phenomena here described is that the motion of the greater number of the glands did not begin till after the insect had become comparatively motionless; and therefore it is very difficult to attribute it to the excitement caused by the struggles on any "contractile tissue" at the base of the gland's, an explanation which has been offered for the sudden and rapid motions of the stamens of Berheris or the leaves of Mimon. It is also quite certain that the impinging of raindrops on the surface of the leaf causes no similar motion, a peculiarity similar to that which Darwin has observed in the case of the motions of tendrils and of climbing stems. In order to determine what share in these motions of the glanis was due to the organic nature of the substance imprisoned, and to its porrer of motion, the following experiments were also made :-A small piece of raw meat was placed on another leaf similar to the first. No immediate change was ohservable, and no increased flow of the secretion; but after the lapse of a few hours a perceptible inclination of the more distant glands towards the object took place. The next morning the piece of meat was found, like the fly, sunk down on to the surface of the leaf, with almost the whole of the glands converging towaris it and above it in just the same manner. The changes here were therefore perfectly of the same kind as in the case of the fly, though apparently somewhat slower. After the lapse of twenty-four hours the piece of meat appeared decilediy lig'iter in cilour; but an accident prevented the process of digestion being further traced. On other leaves 
were placed a minute piece of wood and a small piece of worsted: and in neither of these cases was the least change perceptihle after the lapse of a considerable time in the position of the object, nor in that of any of the glan 1s, either those in contact with it or the more remote ones. It would appear, therefore, that the organised structure of the fly and of the piece of raw meat had some power of excitiny this motion which is not possessed by matter of a different description.

\section{SCIENTIFIC SERIAIS}

Posientorff's Awna!n der Physic und Chemic, No. 6. IS73.This number commences with a paper hy M. Seebeck, on the motinn of sound in hent and hranching tubes. II finds, amorg other thiness, that the gratual hending of a tube hes little effect on the size of wavelength, but if a tulic be suddenly bent to an angle, the sound-motion is considerably affected; $\mathrm{i}^{+}$would seem that the motion of the air-particles did not suddenly alter in direction with the tube. $-A$ series of experiments on the electromotive and thermo-electric fories of some metallic alloys, on contact with copper, is detailed by M. Suniell. The alloys examined were bismuth-tin, bismuth-antimony (in varions proportions), and German silver; the method employed in the case of electromotive force being that of Eiluand, irsed on the fact, that a galvanic curren', pasing through an electromntor, produces in it, proporitionally to its electromotive f:rce, an absorption or protuction of heat, according as the current is in the same direction as that of the electromotor, or contrang to it. The alloys, like the pure metals, have the same order in electromotive as in thermo-electric series; and it appears that the proportion of thermo-clectric to electromotive force is constant, and equal to that for the combinations iron-copper, and copper-bismuth. Comparative experiments on various pyrometric methods-air tl.ermometer, expansion of solitl bodite, cilorimeter, dis=ocintion of a compont, and electrical re istance, leard M. Weinhold to a preference for the last (or Sie nens'), as the moit relialile. The calorimeter, proptrly used, als i gire: Loud resilts.-M. Lorenz, of Copenhacren, furnishes a new det:rmination of the electrical resistance of mercury, in absolute 3nensire. IIe attributes the discordance in previous re-ults to the employment of induced currents, of arariable strenith, and he alopts an ing-nions method in which a constunt electromotive force zithout current, is applien. The result of five experiments is I mercury unit $=0$ (1)337 Ohm's unit, or th: mercury unit equal to $0.9337 .10^{10}$ ab-olute units -Of the remzining prapers we may note one by Kohlrausch on the electrorinemical e quivalent of silver, and mineralogical notes on wolfram, and on a new mineral, ardenite.

\section{SOCIETIES AND ACADELIIES}

\section{LoNien}

Royal Horticultural Society.-General Meetin r, Aug. 20. -IV. A. Lindary, Secretary, in the chair. - The Kev. AI. J. Berkeley said Kerson's seedling: goose'berry, a fine variety which grined a first-class certificate at the last meeting, turned out to be not a garden seadliner but one originally talien from a common hedge in the nei ghbo:rrhond of Pterborough. Tnis was not 2 solitary inst.mee of a fine variety of fruit being foun 1 in such jlaces - the Bess Poul apple having been diccovered in a plantation at Nottingharn. Mr. Berkeley then alluded to a disease of the crocus very destructive to the gladiolus, and which also attacked the saffron crocus and the narcissus; it was first described by Montague under the name of Tacon. He conclided hy remarking that vegetables treated with sewaye were apr to be much deteriorated in liavour.

Sept. 3--General Mecting-Dr. Kellock in the chair. - Advert'ng aytain to the su'vject of Facon in the Gladiolu; the Rev. i. J. Berke ey was i clined to atiribute it to "sunstroke."-A bunch of grapes was exhibited frum the parent plut of the Ilampton Court vine; it da'ed from 176t. - A fungus (Ientznits lepidetus) was sent by Sir Gilbert Scott, from the rojt of a cuurch at Croydon.

\section{PARIS}

Academy of Sciences, Sept. 15.-M. Bertrand in the cliair.-Tire following papers were read :-An answer to Father Tivihini's lase note, bf 31 . liaye. "lite author seplied to the objec ions raised by the Italian observer to the cyclonic theory on the ground of the appearance of prominences where there are no spots. M. Faye considered that the pores, which are vertical cyclones, are the cause of the circulation of the solar hydrogen, and hence of the prominences. He also replied to some objections relating to the direction of the circular motion in cyclonic snots.-New researches on the analysis and the therry of the pulse in normal and abnormal states, by M. Bouillaud. The author announcer the discovery of a secondary beat in the pulse, which he ascribe 1 to a contraction and expansion of the arterics themselves.-On choleraic dejections as agents in the nropagation of cholera, by M. Ch. Pellarin. - On the chrnres of form exhibited by Comet IV., IS73, hy MIM. Rayet and André. - On the movement of an e'astic wire one end of which has a vibratory motion, by M. E. Mercaritier. - On the products of the oxidation of materic irons and a comparison of them with the terrestrial magnetites, by MI. Sran. Meunicr. - Process for tha preparation of a new aniline red, hy M. E. Ferrière. The new colnur is prepared by acting on acetate of aniline with ammoniacal cupric hy trate, and then saturating with sulphuric acid. On concentration anmoniac sulphate is deposited, and the colour remins. It is a purple red.

Sept. 22.-M. Bertrand in the chair. - On the chairman taking his seat, he at once proceeded to announce the deaths of $\mathrm{N1}$. Coite, of the Sectirn of Anatomy and Zonlogy, and of M. Nelaton, of the Section of Me ticine and Surgery; and to express in a few words the sorrow of the Arademy at the grievous loss it had thus sustained. At the conclusion of the chairma's's remarks. M. le IBaron Larrey at nnce proposed that, to mark its sense of the double loss, the Academy should not hear any papers at the meeting, and thit the correspondence only shouht appear in the Comftes Rendus. The following papers were accordingly printed:-Thermic researches on the condensation of grases by solids - continuation: absorption of hydrosen by platimum-black, loy M. I'. A. Favre.-Certain observations on the winged form of the Phyllaxira zilastatrix in connection with the propagation of th $\rightarrow$ insect, by M. Max. Cornu.-On the proper time for the application of the submersion treatment to vines tainted by Phylloxera, by M. L. Faucon.-On the proportion of carlonic anhydri ie in atmospheric air, and on its variation with the altitude, by:I. P. Truchor. The author finds that the quantity of this gas diminishes as the altitute increases. - On coralline, by II. Conmaille. - Note on a meterrite with a phosph.rescent train seen on the night of Eeptemher $2 S, 1 S 73$, by M. Criapelas. -The second part of M. Mercadier's note on the movement of an elastic wire, one end of which is endued with a vibratury motion.

\section{BOOKS RECEIVED}

F.solish-Centrifuzal Force and Gravitation: Joha IH sric (Supp'ement A.)--Ha!! Hours with the Microscops. New Edition (Haruwicke) Zojlo oical Record, Vol. viii, Edied by" Prof Newton (Van loor t). - Chap. ters un Trees: Mr. and E. Kirzy Cusselli). The Amsteur Greenhouse an Conservatory: Sharley Hibberd (Grombrid re)-Proceedings of the Literary and Philosophical Suciety of Liverpool, Yol. xxti. (Long,n
A Discourse on the Pursutt of Truth: A. Elley Finch (Longman).

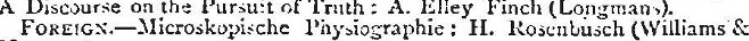
ForEIG:

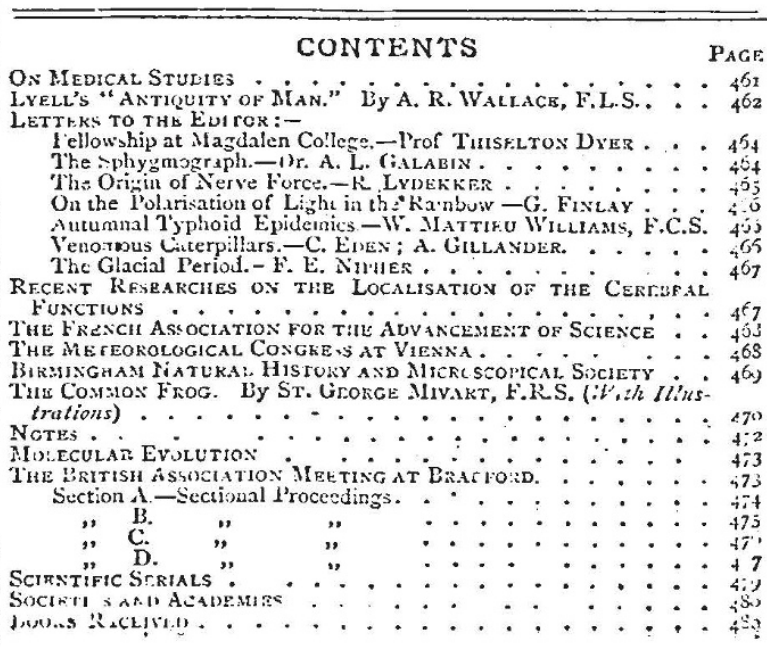

